\section{Reforms set to seep into India's schools}

A culture of rote learning in Indian schools could be partly to blame for the "copy and paste" mentality that undermines the country's research (see A. Chaurasia Nature 534, 591; 2016). Instead, children should be learning the importance of critical thinking, problem-solving and real-life application.

Attempts to abolish rote learning so far extend only to private schools (see go.nature. com/2am4jdb). However, many more children stand to gain from the innovative non-government education initiative Ekal Vidyalaya, which uses a creative educational approach through a system of one-teacher schools in rural areas and tribal villages (www.ekal.org).

Early results of public consultations by the government's Committee for Evolution of the New Education Policy and its Framework for Action promise other alternatives (see go.nature. com/2au3pej). And the 13 bold themes related to school education that have been identified as areas for improvement (see go.nature. com/2aurjby) should enable a new future.

Sanchit Misra Banaras Hindu University, Varanasi, India. imsam93new@gmail.com

\section{Kudos for female Antarctic researchers}

Women scientists were prohibited from working in Antarctica until Soviet geologist Maria Klenova began her research there in 1956. Despite their contributions since, women comprise only $11 \%$ of medal winners from the Scientific Committee on Antarctic Research. Our aim is to raise the profile of influential female researchers to inspire the roughly $60 \%$ of early-career polar scientists who are women.

Notable contributions by women include the discovery of potential methane reservoirs beneath Antarctica ( 5 female authors out of 13: J. L. Wadham et al. Nature 488, 633-637; 2012); the finding that snow melting accelerated in the twentieth century ( 4 of 9 authors: N. J. Abram et al. Nature Geosci. 6, 404-411; 2013); and insights into life in the deep Southern Ocean (12 of 21: A. Brandt et al. Nature 447, 307-311; 2007). The directors of the two largest polar institutes, the British Antarctic Survey and the Alfred Wegener Institute in Germany, are women.

To boost recognition of such achievements, we are writing referenced biographies for prominent female Antarctic scientists, and have received 170 nominations from 30 countries (see go.nature. com/2azwkjq). Examples include In-Young Ahn of the Korea Polar Research Institute, the first Asian woman to lead an Antarctic station, and Lois Jones, who in 1969 led the first all-female Antarctic research team. Jan Strugnell ${ }^{*}$ La Trobe University, Melbourne, Australia. j.strugnell@latrobe.edu.au ${ }^{*}$ On behalf of 7 correspondents (see go.nature.com/2akdzbd for full list).

\section{Funding: would Mendel have won it?}

The finding that interdisciplinary research has low funding success touches a sore spot in molecular biology (see L. Bromham et al. Nature 534, 684-687; 2016). The skilful integration of physics, mathematics and biology that led to the development of molecular biology is being superseded by the use of bioinformatics tools that can process and visualize large amounts of experimental data. Yet these tools often deliver only incremental advances in complex topics (for instance, in the function of transcriptional networks).

Genuinely interdisciplinary landmark discoveries include the stochastic nature of gene expression and the realization that biological systems are 'noisy' (M. B. Elowitz et al.
Science 297, 1183-1186; 2002), and the finding that there was interbreeding between Neanderthals and ancestors of modern humans (R. E. Green et al. Science 328, 710-722;

2010). That discovery relied on sophisticated sample-preparation methods and advanced statistical analysis to reconstruct the flow of genetic material between ancient genomes.

Historically, scientific curiosity has been driven by interdisciplinary knowledge. Gregor Mendel, for example, trained as a physicist. Modern teaching tends to gloss over the mathematical insights that his theory of inheritance required. I suspect that few biologists today could identify binomial distributions in pea-plant cross-breeding experiments and conclude that independent alleles are randomly segregated. Daniel Hebenstreit University of Warwick, Coventry, UK. d.hebenstreit@warwick.ac.uk

\section{Funding: spot value in grant proposals}

Interdisciplinary projects might have more funding success if some review-panel members had interdisciplinary research experience (see L. Bromham et al. Nature 534, 684-687 (2016) and go.nature.com/2at80wd).

Such reviewers are more likely to grasp the importance of lines of investigation that fall outside disciplines. Our study on the feasibility of treating heroin users with pharmaceutical heroin, for example, called for research into whether this perceived permissiveness might influence illicit drug use and have a 'honeypot' effect (G. Bammer Palgrave Commun. 2, 16017; 2016).

Interdisciplinary reviewers also recognize that disciplinary research that is not cutting-edge can still warrant funding if it sheds light on an interdisciplinary problem. Our insights into heroin-addiction treatment came from, among others, economists who determined the likely impact on the drug market; demographers who estimated the number of heroin users; and philosophers who assessed the ethics of prescribing heroin.

The grant-review process could be improved if disciplinary and interdisciplinary panel members had a better understanding of how their views interact, and if guidelines could be drawn up for their relative contributions to the overall assessment.

Gabriele Bammer Australian National University, Acton, Australia.

gabriele.bammer@anu.edu.au

\section{Satellite company clarifies proposal}

As chief executive of the satellitecommunications company Ligado Networks, I wish to emphasize that our proposed sharing of a small block of radio frequencies with the US National Oceanic and Atmospheric Association (NOAA) will not jeopardize the delivery of weather information from satellites (see Nature 535, 208-209; 2016).

We are exploring this idea through open dialogue with the US Federal Communications Commission, NOAA and the weather community. The company was invited to discuss radio frequencies at an American Meteorological Society meeting last month, and feedback on our plan's potential impact is allowing us to home in on remaining concerns and discuss solutions.

We are also exploring an alternative network for providing real-time weather data to more users at a lower cost. This would protect NOAA's existing uses of the band and expand the availability of a high-demand wireless spectrum. Our technology could deliver reliable, secure connectivity to critical industries, including those that serve public safety.

Doug Smith Ligado Networks, Reston, Virginia, USA. spectrum@ligado.com 